\title{
Effects of the blood urea nitrogen to creatinine ratio on haemorrhagic transformation in AIS patients with diabetes mellitus
}

Linghui Deng ${ }^{1+}$, Shi Qiu ${ }^{2,3+}$, Changyi Wang ${ }^{1 \dagger}$, Haiyang Bian ${ }^{4}$, Lu Wang ${ }^{1}$, Yuxiao Li ${ }^{1}$, Bo Wu ${ }^{1 *}$ and Ming Liư ${ }^{1 *}$

\begin{abstract}
Background: The effect of the blood urea nitrogen (BUN) to creatinine $(\mathrm{Cr})$ ratio (henceforth $\mathrm{BUN} / \mathrm{Cr}$ ) on haemorrhagic transformation (HT) of acute ischaemic stroke (AIS) patients is unclear.

Methods: AIS patients in the West China Hospital, Sichuan University, Chengdu, China, admitted within seven days from stroke onset (2012-2016) were included in the study. Baseline data, including BUN and Cr levels, were collected. The outcome was defined as HT during hospitalization.

Results: In this study, 1738 participants with an average age of $62.7 \pm 14.0$ years were included. After adjusting potential confounders (age, blood platelet, albumin, stroke severity, triglycerides and low-density lipoprotein [LDL]), multivariate logistic regression analyses indicated that BUN/Cr is independently associated with HT. The nonlinear relation between BUN/Cr and $\mathrm{HT}$ was explored in a dose-dependent manner, with an apparent inflection point of 30.71. On the left and right sides of the inflection point, the odds ratio (OR) and $95 \%$ confidence interval (Cl) were 1.05 (1.02-1.08) and $0.96(0.88-1.05)$, respectively. Interaction between BUN/Cr and diabetes mellitus (DM) and HT ( $P$ for interaction $=0.0395)$ was noted. BUN/Cr showed positive correlation with $\mathrm{HT}$ in DM patients $(\mathrm{OR}=1.07 ; 95 \% \mathrm{Cl}$ : $[1.02,1.12])$ but no significant relationship with $H T$ in patients without DM.

Conclusion: BUN/Cr is significantly associated with HT in AIS patients in a linear fashion, with an apparent cut point demarcating the HT difference. When the patients have DM, BUN/Cr is positively correlated with HT. These results support a revision in how we anticipate the prognosis for AIS patients.
\end{abstract}

Keywords: Blood urea nitrogen, Creatinine, Ischaemic stroke, Haemorrhagic transformation, Nonlinear relationship

\section{Background}

Acute ischaemic stroke (AIS) is a devastating condition with high mortality and morbidity, which is often complicated by haemorrhagic transformation (HT) and is potentially linked to clinical deterioration $[1,2]$. The active exploration of the risk factors for HT has clinical significance as it could help clinicians identify potential risks, adjust the therapeutic schedule, reduce the occurrence of $\mathrm{HT}$ and consequently improve the quality of life

\footnotetext{
* Correspondence: wyplmh@hotmail.com; dragonwb@126.com

† Linghui Deng, Shi Qiu and Changyi Wang contributed equally to this work.

${ }^{1}$ Center of Cerebrovascular Diseases, Department of Neurology, West China

Hospital, Sichuan University, Chengdu, Sichuan, China

Full list of author information is available at the end of the article
}

for patients. Approximately $30 \%$ of AIS patients present with renal dysfunction [3], which is considered an independent prognostic indicator of poor clinical outcomes [4]. Exploring biomarkers of kidney impairment could be helpful to evaluating cerebral microvascular risk and correlation of stroke complications [5]. Studies have demonstrated that the estimated glomerular filtration rate (eGFR) is associated with HT [6, 7]. Besides the eGFR, blood urea nitrogen $(\mathrm{BUN})$ and creatinine $(\mathrm{Cr})$ are also used for evaluating renal function.

Recently, the BUN-to-Cr ratio (BUN/Cr) has emerged as an independent prognostic indicator of poor outcomes in different disease conditions, such as acute and chronic heart failure [8-11], acute and chronic kidney

(c) The Author(s). 2019 Open Access This article is distributed under the terms of the Creative Commons Attribution 4.0 International License (http://creativecommons.org/licenses/by/4.0/), which permits unrestricted use, distribution, and 
injury [12, 13] and ischaemic stroke [14]. Studies have indicated that an elevated BUN/Cr may be a potential marker for early neurological deterioration and a three-month outcome in AIS patients [14-18]. In addition, an elevated $\mathrm{BUN} / \mathrm{Cr}$ is reportedly an independent risk factor for venous thromboembolism in AIS patients [19]. However, there was no research focusing on the association between $\mathrm{BUN} / \mathrm{Cr}$ and the risk of $\mathrm{HT}$ in AIS. Therefore, in this study, we investigated the association between BUN/Cr and HT in AIS patients.

\section{Methods}

\section{Study population}

In this study, we included adult patients admitted to West China Hospital, Sichuan University, Chengdu, China, within 7 days of first-ever AIS onset between January 2012 and December 2016. Given the retrospective nature of the study, requirement for informed consent was waived by the Institution review board of of West China Hospital, Sichuan University, Chengdu, People's Republic of China. All patients were diagnosed with AIS on the basis of the World Health Organization criteria and the Trial of Org 10,172 in Acute Stroke Treatment criteria [20, 21]. The diagnosis was further confirmed by magnetic resonance imaging (MRI) or computed tomography $(\mathrm{CT})$. The patients were entered consecutively and prospectively into the Chengdu Stroke Registry [22]. Informed consent of the patients was not needed, because the current study was a database-based analysis not experimental research on humans. Patients were, however, excluded from the study if: (i) they were diagnosed with primary subarachnoid haemorrhage or intracerebral haemorrhage on the basis of first-time head CT scans (ii) they had severe liver disease or end-stage renal disease or (iii) their BUN or $\mathrm{Cr}$ values were unavailable on admission.

\section{Data collection and outcome}

The following data were collected by reviewing the patients' medical records: demographic characteristics (age and gender), stroke risk factors (history of diabetes mellitus [DM], hypertension, dyslipidaemia, atrial fibrillation [AF], smoking status, alcohol consumption), interval of symptom onset, stroke severity on admission and laboratory data. In addition, the data on stroke severity was assessed using the National Institutes of Health Stroke Scale (NIHSS) from the case files [23]. HT was defined as haemorrhage inside the infarct region or parenchyma outside the infarct territory on a follow-up CT or MRI [24].

\section{Statistical analysis}

In this study, data were presented as mean \pm standard deviation (normal distribution) or median (quartile; skewed distribution) for continuous variables and as a frequency or a percentage for categorical variables. The statistical difference between within-population characteristics were determined using analysis of variance (normal distribution), Kruskal-Wallis $H$ test (skewed distribution) and chi-squared test (categorical variables). The statistical software packages used were $\mathrm{R}$ (http://www.R-project.org, The $\mathrm{R}$ Foundation) and EmpowerStats (http://www. empowerstats.com, X\&Y Solutions, Inc., Boston, MA, USA). First, we used a univariate linear regression model to assess the relationship between BUN/Cr and HT. Both univariate and multivariate models with crude and adjusted odds ratios (ORs) were listed. We used the generalized additive model (GAM) model to adjust the continuous variables in the model II. Covariates significantly associated with the response variable $(P<0.05)$ or changed the effect estimate by $10 \%$ or more were retained in the final adjusted model [25]. Second, we used the GAM to identify the nonlinear relationship between $\mathrm{BUN} / \mathrm{Cr}$ and $\mathrm{HT}$. If a nonlinear correlation was detected, a two-piecewise linear regression model was then used to determine the threshold effect of BUN/Cr on HT in accordance with the smoothing plot. When the BUN/Cr:HT ratio appeared obvious in the smoothing plot, the inflection point was figured automatically by the recursive method using the maximum model likelihood [26]. Finally, we inspected the modification and interaction of subgroups using the likelihood ratio test. Two-tailed $P<$ 0.05 was considered statistically significant.

\section{Results}

\section{Study participants and baseline characteristics}

Of the 3458 participants in the Chengdu Stroke Registry, our data analyses were limited to 1738 subjects from West China Hospital. Please refer to Additional file 1: Figure $\mathrm{S} 1$ for a flowchart. The average age of the participants was $62.7 \pm 14.0$ years, and $\sim 60.2 \%$ of them were male. The average baseline NIHSS was $6.53 \pm 6.26$. Table 1 lists the baseline characteristics. Compared to the high level (T3) of BUN/Cr group, participants in the other two groups (T1 and T2) were younger and had a higher percentage of males, higher baseline $\mathrm{Cr}$ and higher alcohol intake; were smokers; had a lower baseline NIHSS, BUN and high-density lipoprotein (HDL); and had a lower rate of history of AF and severe stroke.

\section{Univariate analysis}

A univariate linear regression model was used to evaluate the association between BUN/Cr and HT. Additional file 1: Table S1 summarizes the results of the analysis. The analysis revealed that age, a history of AF and stroke severity are correlated with a higher risk of HT, whereas baseline blood platelet, albumin, cholesterol and low-density lipoprotein (LDL) levels are associated with a lower risk of HT (Additional file 1: Table S1). 
Table 1 Baseline Characteristics of participants

\begin{tabular}{|c|c|c|c|c|}
\hline $\mathrm{BUN} / \mathrm{Cr}$ & Tertile 1 & Tertile 2 & Tertile 3 & $P$-value \\
\hline N & 578 & 580 & 580 & \\
\hline Age (years, mean \pm sd) & $59.96 \pm 14.56$ & $63.24 \pm 13.96$ & $64.92 \pm 13.06$ & $<0.001^{*}$ \\
\hline Male,n (\%) & $438(75.78 \%)$ & $369(63.62 \%)$ & $240(41.38 \%)$ & $<0.001^{*}$ \\
\hline Intervals between symptoms onset to admission (minutes, mean \pm sd) & $60.90 \pm 47.73$ & $60.05 \pm 48.94$ & $62.87 \pm 51.11$ & 0.61 \\
\hline Baseline NIHSS score (mean \pm sd) & $5.65 \pm 5.80$ & $6.46 \pm 6.20$ & $6.90 \pm 6.58$ & $<0.01^{*}$ \\
\hline Blood platelet $\left(* 10^{9} / \mathrm{L}\right.$, mean $\left.\pm \mathrm{sd}\right)$ & $173.33 \pm 69.14$ & $165.83 \pm 60.51$ & $168.80 \pm 64.37$ & 0.14 \\
\hline Albumin $(\mathrm{g} / \mathrm{L}$, mean $\pm \mathrm{sd})$ & $40.84 \pm 4.53$ & $41.00 \pm 4.48$ & $40.45 \pm 4.66$ & 0.11 \\
\hline BUN $(\mathrm{mg} / \mathrm{dL}$, mean $\pm \mathrm{sd})$ & $13.30 \pm 6.80$ & $16.17 \pm 4.76$ & $20.70 \pm 6.90$ & $<0.001^{*}$ \\
\hline $\mathrm{Cr}(\mathrm{mg} / \mathrm{dL}$, mean $\pm \mathrm{sd})$ & $1.09 \pm 0.70$ & $0.92 \pm 0.27$ & $0.81 \pm 0.27$ & $<0.001^{*}$ \\
\hline Triglyceride (mmol/L, mean $\pm \mathrm{sd})$ & $1.64 \pm 1.16$ & $1.60 \pm 1.06$ & $1.55 \pm 1.12$ & 0.38 \\
\hline Total cholesterol $(\mathrm{mmol} / \mathrm{L}$, mean $\pm \mathrm{sd})$ & $4.41 \pm 1.11$ & $4.44 \pm 1.13$ & $4.43 \pm 1.10$ & 0.90 \\
\hline $\mathrm{HDL}(\mathrm{mmol} / \mathrm{L}$, mean $\pm \mathrm{sd})$ & $1.27 \pm 0.38$ & $1.29 \pm 0.38$ & $1.32 \pm 0.41$ & $<0.05^{*}$ \\
\hline $\mathrm{LDL}(\mathrm{mmol} / \mathrm{L}$, mean $\pm \mathrm{sd})$ & $2.60 \pm 0.95$ & $2.66 \pm 0.97$ & $2.59 \pm 0.93$ & 0.46 \\
\hline Hypertension, n (\%) & $278(48.10 \%)$ & $296(51.03 \%)$ & $290(50.00 \%)$ & 0.60 \\
\hline Diabete Mellitus, n (\%) & $89(15.40 \%)$ & $112(19.31 \%)$ & $119(20.52 \%)$ & 0.06 \\
\hline Hyperlipidemia, n (\%) & $30(5.19 \%)$ & $27(4.66 \%)$ & $27(4.66 \%)$ & 0.89 \\
\hline Atrial Fibrillation, n (\%) & $25(4.33 \%)$ & $45(7.76 \%)$ & $64(11.03 \%)$ & $<0.001^{*}$ \\
\hline Alcohol intake, n (\%) & 185 (32.01\%) & $156(26.90 \%)$ & $104(17.93 \%)$ & $<0.001^{*}$ \\
\hline Current smoking, n (\%) & $249(43.08 \%)$ & $211(36.38 \%)$ & $145(25.00 \%)$ & $<0.001^{*}$ \\
\hline Stroke severity & & & & $<0.01^{*}$ \\
\hline Baseline NIHSS score < 15, n (\%) & $530(91.70 \%)$ & 519 (89.48\%) & 499 (86.03\%) & \\
\hline Baseline NIHSS score > =15, n (\%) & $48(8.30 \%)$ & $61(10.52 \%)$ & $81(13.97 \%)$ & \\
\hline
\end{tabular}

* Represents the unit of blood platelet e.g., the normal range of blood platelet is $4-10 * 10^{9} / \mathrm{L}$

BUN Blood urea nitrogen, Cr Creatinine, NIHSS National Institutes of Health Stroke scale, HDL High-density lipoprotein, LDL Low-density lipoprotein

\section{Results of analysis of the BUN/Cr-HT relationship}

As shown in Table 2, BUN/Cr displayed a positive correlation with $\mathrm{HT}$ in the crude model $(\mathrm{OR}=1.03$; 95\% CI: [1.01-1.05]; $P=0.0019)$. In the adjusted model (age, blood platelet, albumin, baseline NIHSS, triglycerides and LDL), the result remained stable $(\mathrm{OR}=1.02 ; \quad 95 \%$ CI: $[1.00-1.05] ; \quad P=0.03)$. For sensitivity analysis, $\mathrm{BUN} / \mathrm{Cr}$ was considered a categorical variable (tripartite) and a similar trend was found ( $P$ for trend $<0.01$; see Table 2 ).

\section{Analyses of the BUN/Cr-HT nonlinear relationship}

It is essential to analyse nonlinear relationships for continuous variables. In this study (Fig. 1), we detected a nonlinear relationship between $\mathrm{BUN} / \mathrm{Cr}$ and $\mathrm{HT}$ after adjusting the age, blood platelet, albumin, stroke severity, triglycerides and LDL. Using the two-piecewise linear regression model, we calculated the inflection point as 30.71 . The OR $(95 \%$ $\mathrm{CI})$ and $P$ values were $1.05(1.02,1.08)$ and 0.0029 , respectively, on the left of the inflection point. However, on the right of the inflection point, the $\mathrm{BUN} / \mathrm{Cr}-\mathrm{HT}$ relationship

Table 2 Relationship between BUN/Cr and HT in different models

\begin{tabular}{llll}
\hline Variable & Crude model $(\beta, 95 \% \mathrm{Cl}, P)$ & Model I $(\beta, 95 \% \mathrm{Cl}, P)$ & Model II $(\beta, 95 \% \mathrm{Cl}, P)$ \\
\hline BUN $/ \mathrm{Cr}$ & $1.03(1.01,1.05)<0.01$ & $1.03(1.00,1.05) 0.02$ & $1.02(1.00,1.05) 0.03$ \\
BUN $/ \mathrm{Cr}$ (tertile) & & & \\
T1 & Ref & Ref & Ref \\
T2 & $0.97(0.61,1.53) 0.89$ & $0.89(0.56,1.42) 0.63$ & $0.89(0.56,1.42) 0.63$ \\
T3 & $1.88(1.25,2.82)<0.01$ & $1.63(1.08,2.47) 0.02$ & $1.62(1.07,2.45) 0.02$ \\
\hline
\end{tabular}

$p$ for trend $,<0.01,<0.01,<0.01$

Crude model: we did not adjust other covariants

Model I: we adjusted Age; Blood platelet; Albumin; Stroke severity; Triglyceride; LDL

Model II: we adjusted Age (Smooth); Blood platelet (Smooth); Albumin (Smooth); Stroke severity; Triglyceride (Smooth); LDL (Smooth).LDL = low-density lipoprotein $\mathrm{Cl}$ Confidence interval, Ref Reference, BUN Blood urea nitrogen, $\mathrm{Cr}$ Creatinine 


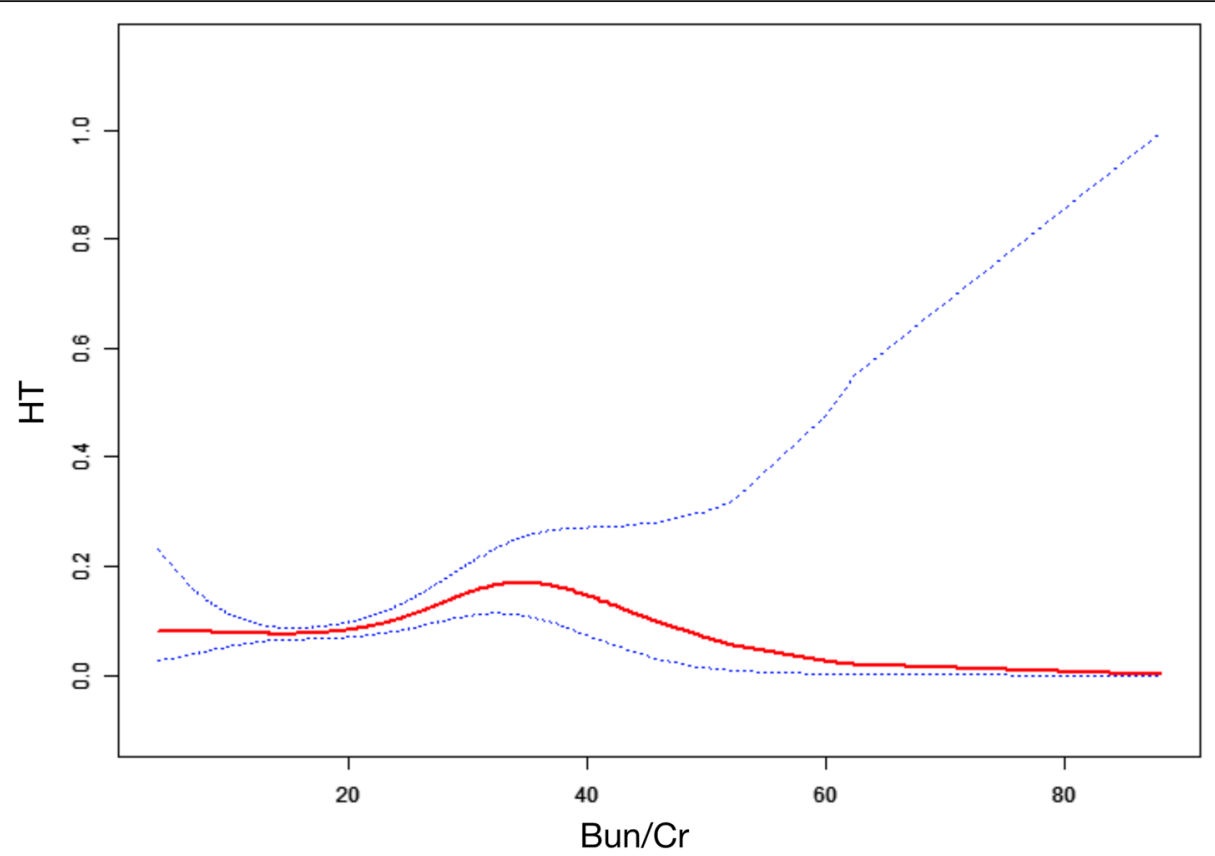

Fig. 1 The non-linear relationship between Bun/Cr and HT

displayed insignificant values: $\mathrm{OR}=0.96 ; 95 \% \mathrm{CI}:(0.88$, 1.05); $P=0.36$. See Fig. 1 and Table 3.

\section{Subgroup analyses}

The results of our subgroup analyses are presented in Table 4. After adjusting potential confounders, we found that the test for interaction was statistically significant for a history of DM ( $P$ for interaction $=0.04)$ but not for age, sex, history of hypertension, hyperlipidaemia, AF, blood platelet, albumin, stroke severity, triglycerides, total cholesterol, HDL and LDL. We also found evidence of BUN/ $\mathrm{Cr}-\mathrm{DM}$ interaction. The effect of BUN/Cr on HT significantly differed between patients with and without DM. BUN/Cr had a positive correlation with $\mathrm{HT}(\mathrm{OR}=1.07$, 95\% CI: $[1.02,1.12])$ in DM patients but no significant relationship with $\mathrm{HT}$ in patients without DM. Moreover, we observed that BUN/Cr was positively correlated with $\mathrm{HT}$ when BUN/Cr was less than 30.71 (Table 4).

\section{Discussion}

This study revealed that BUN/Cr is significantly associated with HT in a linear fashion in AIS patients, with an apparent inflection point demarcating the HT difference. These results support a revision in how we anticipate the

Table 3 The results of two-piecewise linear regression model

\begin{tabular}{lll}
\hline Inflection point of BUN/Cr & Effect size $(95 \% \mathrm{Cl})$ & $P$ value \\
\hline$<30.71$ & $1.05(1.02,1.08)$ & $<0.01$ \\
$>30.71$ & $0.96(0.88,1.05)$ & 0.3629 \\
\hline
\end{tabular}

Low-density lipoprotein, BUN Blood urea nitrogen, $\mathrm{Cr}$ Creatinine

Adjust: Age; Blood platelet; Albumin; Stroke severity; Triglyceride; LDL. LDL prognosis for AIS patients. In addition, we found an interaction between BUN/Cr and DM and HT ( $P$ for interaction $=0.04)$. BUN/Cr had a positive correlation with HT $(\mathrm{OR}=1.07$; 95\% CI: $[1.02,1.12])$ in DM patients but no significant relationship with HT in patients without DM.

As mentioned before, an elevated BUN/Cr indicates serious medical conditions and poor prognosis in patients with acute kidney injury and acute heart failure $[8,12]$. Previous studies have shown that impaired kidney function involves an excess risk of bleeding, which might contribute to platelet dysfunction coupled with abnormal platelet-blood vessel wall interaction [27]. Renal dysfunction has also been reported to be linked with small-vessel cerebrovascular disease and increased risk of haemorrhagic microangiopathy, which might be eventually attributable to cerebral haemorrhage [28-31]. Therefore, an elevated BUN/Cr might explain why the risk of $\mathrm{HT}$ increases in AIS patients. In addition, kidney impairment has been linked to inflammation as well as endothelial dysfunction. Microinflammation in kidney impairment might improve vascular activation and leukocyte infiltration in the etiopathogenesis of HT. Finally, bleeding in patients with kidney impairment might be due to a disturbance in the coagulation system [29]. On the basis of our data and these existing reports, we speculate that an elevated BUN/Cr increases the risk of HT probably by increasing the prevalence of small-vessel cerebrovascular disease. This should be confirmed directly by the biomarkers of small-vessel diseases.

It is essential to explore subgroup analyses for a scientific study [32]. In this study, we found that an elevated 
Table 4 Effect size of BUN/Cr on HT in prespecified and exploratory subgroups

\begin{tabular}{cllc}
\hline Characteristic & $\begin{array}{l}\text { No of } \\
\text { participants }\end{array}$ & $\begin{array}{l}\text { Effect size }(95 \% \mathrm{Cl}), \\
p \text { value }\end{array}$ & $P$ for interaction \\
\hline BUN $/ \mathrm{Cr}$ & & & $0.02^{*}$ \\
$<30.71$ & 1644 & $1.04(1.00,1.07), 0.04$ & \\
30.71 & 89 & $0.91(0.80,1.03), 0.15$ &
\end{tabular}

$\begin{array}{ccc}\begin{array}{c}\text { Age (year) } \\ <65\end{array} & 910 & 1.01(0.98,1.05), 0.51 \\ \begin{array}{c}\text { \65 } \\ \text { Sex }\end{array} & 823 & 1.04(1.01,1.07), 0.01 \\ \text { Female } & 689 & 1.02(0.99,1.05), 0.11 \\ \text { Male } & 1044 & 1.03(0.99,1.07), 0.19\end{array}$

Hypertention

$\begin{array}{lll}\text { No } & 873 & 1.03(1.00,1.06), 0.03 \\ \text { Yes } & 860 & 1.02(0.98,1.05), 0.41\end{array}$

Diabetes Mellitus

$\begin{array}{ll}\text { No } & 1415 \\ \text { Yes } & 318\end{array}$

Hyperlipidemia

No 1651

Yes 82

Atrial Fibrillation

No 1599

Yes 134

Alcohol intake

No $\quad 1288$

Yes $\quad 445$

Current smoking

$\begin{array}{ll}\text { No } & 1129 \\ \text { Yes } & 604\end{array}$

Stroke severity

$\begin{array}{ll}\text { No } & 1543 \\ \text { Yes } & 190\end{array}$

Blood platelet

No 864

Yes $\quad 869$

Albumin

Yes 873

Triglyceride

$\begin{array}{ll}\text { Low } & 867 \\ \text { High } & 866\end{array}$

Total cholesterol

$\begin{array}{ll}\text { Low } & 866 \\ \text { High } & 867\end{array}$

$1.01(0.99,1.04), 0.39$

$1.07(1.02,1.12),<0.01$

0.22

$1.03(1.01,1.05), 0.02$

$0.87(0.68,1.12), 0.29$

$1.02(1.00,1.05), 0.09$

$1.05(0.99,1.12), 0.07$

$1.02(1.00,1.05), 0.07$

$1.03(0.98,1.08), 0.19$

$1.03(1.01,1.05), 0.02$

$1.01(0.96,1.06), 0.69$

$1.03(1.00,1.06), 0.03$

$1.02(0.98,1.05), 0.30$

$1.02(0.99,1.04), 0.29$

$1.04(1.00,1.08), 0.03$

$1.01(0.99,1.04), 0.33$

$1.04(1.01,1.08), 0.02$
$1.03(0.99,1.07), 0.11$
Table 4 Effect size of BUN/Cr on HT in prespecified and exploratory subgroups (Continued)

\begin{tabular}{cllc}
\hline Characteristic & $\begin{array}{l}\text { No of } \\
\text { participants }\end{array}$ & $\begin{array}{l}\text { Effect size }(95 \% \mathrm{Cl}), \\
p \text { value }\end{array}$ & $P$ for interaction \\
\hline HDL & & & 0.59 \\
Low & 855 & $1.02(0.99,1.05), 0.23$ & \\
High & 878 & $1.03(1.00,1.06), 0.04$ & \\
LDL & & & 0.93 \\
Low & 865 & $1.02(1.00,1.05), 0.06$ & \\
High & 868 & $1.03(0.99,1.07), 0.18$ &
\end{tabular}

BUN Blood urea nitrogen, $\mathrm{Cr}$ Creatinine, HDL High-density lipoprotein, $L D L$ Low-density lipoprotein

Note 1: Above model adjusted for Age; Blood platelet; Albumin; Stroke severity; Triglyceride; LDL

Note 2:In each case, the model is not adjusted for the stratification variable

BUN/Cr has a positive correlation with HT in AIS patients with DM. About 30\% of AIS patients have DM, and diabetics suffer the worst clinical outcomes from strokes [33, 34]; therefore, improving outcomes in the diabetic subgroup is of great importance. Studies have established a close link between HT and arteriosclerosis as well as microvascular impairment [35], which might be induced by persistent high blood glucose. Previous studies have also shown that DM/hyperglycaemia is linked to HT [36-41], indicating that DM might influence the process of haemorrhaging. With relative microvascular fragility [42], DM might account for earlier and greater cerebrovascular damage in HT patients. Therefore, our results could be interpreted as microvascular damage and arteriosclerosis being the major cause of HT [43-45] and BUN/Cr being an important parameter in appraising chronic vascular complications.

This study had several unique strengths. First, we discovered a nonlinear BUN/Cr-HT relationship, which might contribute to revealing the real association between $\mathrm{BUN} / \mathrm{Cr}$ and HT. The GAM is good at handling nonlinear relationships because it can cope with nonparametric smoothing and configure a regression spline [26]. Second, although potential confounding factors in the study were unavoidable, we used strict statistical adjustment to minimize residual confounding. Third, modifier factor analysis took full advantage of the data. Also, subgroup analysis found a positive correlation of BUN/Cr with HT in DM patients. The study also had several potential concerns or limitations. First, this was an observational analysis and there were some differences in the baseline characteristics among the three patient groups. Second, the study was single-centre-based, so further studies are required in order to verify our extrapolation. The number of patients in each subgroup was relatively low, which might indicate undervaluation of the BUN/Cr-HT relationship. Third, symptomatic haemorrhage was not analysed independently. Four, data 
of a large infarct area, the degree of leukoaraiosis and a combination of biomarkers of small-vessel diseases were not analysed. Finally, the predictive effect of BUN/Cr on HT in different phases of AIS was not disclosed. Therefore, more high-quality studies are required in order to explore the different effects of $\mathrm{BUN} / \mathrm{Cr}$ on $\mathrm{HT}$ in the early and late phases of AIS.

\section{Conclusion}

The results of this study showed that $\mathrm{BUN} / \mathrm{Cr}$ is an independent predictor for $\mathrm{HT}$ in AIS patients. BUN/Cr is positively correlated with HT when patients have DM. Further studies are required in order to elucidate the association between renal insufficiency and HT in terms of clinical outcomes after AIS, in addition to further confirmation of our findings in an independent study.

\section{Additional file}

Additional file 1: Figure S1: Flow chat. Table S1 The results of univariate analysis. (DOCX $231 \mathrm{~kb})$

\section{Abbreviations}

AIS: Acute ischaemic stroke; BUN: Blood urea nitrogen; Cl: Confidence interval; Cr: Creatinine; CT: Computed tomography; DM: Diabetes mellitus; eGFR: Estimated glomerular filtration rate; GAM: Generalized additive model; HDL: High-density lipoprotein; HT: Haemorrhagic transformation; LDL: Lowdensity lipoprotein; MRI: Magnetic resonance imaging; NIHSS: National Institutes of Health Stroke Scale; OR: Odds ratio; ORs: Odds ratios

\section{Acknowledgments \\ Many thank to lan Charles Tobias and Enago (www.enago.cn) for the English language review. This study was supported by Major International (Regional) Joint Research Project, National Natural Science Foundation of China (Grant No. 81620108009), The National Key Research and Development Program of China, Ministry of Science and Technology of China (2016YFC1300500-505),} and National Natural Science Foundation of China (Grant No. 81671146).

\section{Funding}

None.

\section{Availability of data and materials}

The datasets used and/or analysed during the current study are available from the corresponding author on reasonable request.

\section{Authors' contributions}

$M L$ and BW are responsible for the conception and design of the study. SQ, HYB and CYW interpreted the analysis. LHD, CYW, LW and YXL were responsible for the acquisition of data. LHD and SQ wrote the first draft of the manuscript and interpreted the data and wrote the final version. All authors critically revised the Article for important intellectual content and approved the final version. ML obtained public funding.

\section{Ethics approval and consent to participate}

The datasets accessed were de-identified. Given the retrospective nature of the study, requirement for informed consent was waived by the Institution review board of the West China Hospital, Sichuan University, Chengdu, People's Republic of China. Prof. Ming Liu granted permission to access the raw data from the registry. The procedure was approved by the Ethics Committee of the West China Hospital, Sichuan University.

\section{Consent for publication}

Participants consent for publication: Not applicable.

\section{Competing interests}

The authors declare that they have no competing interests.

\section{Publisher's Note}

Springer Nature remains neutral with regard to jurisdictional claims in published maps and institutional affiliations.

\section{Author details}

${ }^{1}$ Center of Cerebrovascular Diseases, Department of Neurology, West China Hospital, Sichuan University, Chengdu, Sichuan, China. ${ }^{2}$ Department of Urology, Institute of Urology, West China Hospital, Sichuan University, Chengdu, Sichuan, China. ${ }^{3}$ Center of Biomedical big data, West China Hospital, Sichuan University, Chengdu, Sichuan, China. ${ }^{4}$ Department of Epidemiology and Biostatistics, School of Public Health, Peking University, Beijing, China.

Received: 31 July 2018 Accepted: 31 March 2019

Published online: 13 April 2019

\section{References}

1. Rao NM, Levine SR, Gornbein JA, Saver JL. Defining clinically relevant cerebral hemorrhage after thrombolytic therapy for stroke: analysis of the National Institute of Neurological Disorders and Stroke tissue-type plasminogen activator trials. Stroke. 2014:45(9):2728-33.

2. Kaesmacher J, Kaesmacher M, Maegerlein C, Zimmer C, Gersing AS, Wunderlich S, Friedrich B, Boeckh-Behrens T, Kleine JF. Hemorrhagic transformations after thrombectomy: risk factors and clinical relevance. Cerebrovasc Dis. 2017:43:294-304.

3. Tsagalis G, Akrivos T, Alevizaki M, Manios E, Stamatellopoulos K, Laggouranis A, Vemmos KN. Renal dysfunction in acute stroke: an independent predictor of long-term all combined vascular events and overall mortality. Nephrol Dial Transplant. 2009;24:194-200.

4. Yahalom G, Schwartz R, Schwammenthal Y, Merzeliak O, Toashi M, Orion D, Sela BA, Tanne D. Chronic kidney disease and clinical outcome in patients with acute stroke. Stroke. 2009:40:1296-303.

5. Castro P, Azevedo E, Rocha I, Sorond F, Serrador JM. Chronic kidney disease and poor outcomes in ischemic stroke: is impaired cerebral autoregulation the missing link? BMC Neurol. 2018;18(1):21.

6. Lee JG, Lee KB, Jang IM, Roh H, Ahn MY, Woo HY, Hwang HW. Low glomerular filtration rate increases hemorrhagic transformation in acute ischemic stroke. Cerebrovasc Dis. 2013;35(1):53-9.

7. Liu B, Wang D, Hao Z, Li D, Zhang J, Liu J, Liu M. Reduction in estimated glomerular filtration rate (eGFR) results in an increased risk of spontaneous hemorrhagic transformation in patients with large-artery atherosclerosis stroke. Curr Neurovasc Res. 2016;13(1):75-81.

8. Matsue $Y$, van der Meer $\mathrm{P}$, Damman $\mathrm{K}$, Metra M, O'Connor CM, Ponikowski P, Teerlink JR, Cotter G, Davison B, Cleland JG, Givertz MM, Bloomfield DM, Dittrich HC, Gansevoort RT, Bakker SJ, van der Harst P, Hillege HL, van Veldhuisen DJ, Voors AA. Blood urea nitrogen-to-creatinine ratio in the general population and in patients with acute heart failure. Heart. 2017; 103(6):407-13.

9. Parrinello G, Torres D, Testani JM, Almasio PL, Bellanca M, Pizzo G, Cuttitta F, Pinto A, Butler J, Paterna S. Blood urea nitrogen to creatinine ratio is associated with congestion and mortality in heart failure patients with renal dysfunction. Intern Emerg Med. 2015;10(8):965-72.

10. Lin HJ, Chao CL, Chien KL, Ho YL, Lee CM, Lin YH, Wu YW, Hsu RB, Chou NK, Wang SS, Chen CY, Chen MF. Elevated blood urea nitrogen-to-creatinine ratio increased the risk of hospitalization and all-cause death in patients with chronic heart failure. Clin Res Cardiol. 2009:98(8):487-92.

11. Sood MM, Saeed M, Lim V, Cordova F, Komenda P, Malik A, Rigatto C, Shafer LA, Tangri N, Tappia PS, Zieroth S. The urea-to-creatinine ratio is predictive of worsening kidney function in ambulatory heart failure patients. J Card Fail. 2015;21(5):412-8.

12. Uchino S, Bellomo R, Goldsmith D. The meaning of the blood urea nitrogen/ creatinine ratio in acute kidney injury. Clin Kidney J. 2012;5(2):187-91.

13. Tanaka S, Ninomiya T, Taniguchi M, Tokumoto M, Masutani K, Ooboshi H, Kitazono T, Tsuruya K. Impact of blood urea nitrogen to creatinine ratio on mortality and morbidity in hemodialysis patients: the Q-cohort study. Sci Rep. 2017;7(1):14901. 
14. Schrock JW, Glasenapp M, Drogell K. Elevated blood urea nitrogen/ creatinine ratio is associated with poor outcome in patients with ischemic stroke. Clin Neurol Neurosurg. 2012;114:881-4.

15. Lin LC, Yang JT, Weng HH, Hsiao CT, Lai SL, Fann WC. Predictors of early clinical deterioration after acute ischemic stroke. Am J Emerg Med. 2011;29:577-81.

16. Lin WC, Shih HM, Lin LC. Preliminary prospective study to assess the effect of early blood urea nitrogen/creatinine ratio-based hydration therapy on Poststroke infection rate and length of stay in acute ischemic stroke. J Stroke Cerebrovasc Dis. 2015;24(12):2720-7.

17. Bhatia K, Mohanty S, Tripathi BK, Gupta B, Mittal MK. Predictors of early neurological deterioration in patients with acute ischaemic stroke with special reference to blood urea nitrogen (BUN)/creatinine ratio \& urine specific gravity. Indian J Med Res. 2015;141:299-307.

18. Liu CH, Lin SC, Lin JR, Yang JT, Chang YJ, Chang CH, Chang TY, Huang KL, Ryu $\mathrm{SJ}$, Lee TH. Dehydration is an independent predictor of discharge outcome and admission cost in acute ischaemic stroke. Eur J Neurol. 2014;21:1184-91.

19. Kim H, Lee K, Choi HA, Samuel S, Park JH, Jo KW. Elevated blood urea nitrogen/creatinine ratio is associated with venous thromboembolism in patients with acute ischemic stroke. J Korean Neurosurg Soc. 2017:60(6):620-6.

20. Aho K, Harmsen P, Hatano S, Marquardsen J, Smirnov VE, Strasser T. Cerebrovascular disease in the community: results of a WHO collaborative study. Bull World Health Organ. 1980;58:113-30.

21. Adams HP Jr, Bendixen BH, Kappelle LJ, Biller J, Love BB, Gordon DL, Marsh EE 3rd. Classification of subtype of acute ischemic stroke. Definitions for use in a multi-center clinical trial. TOAST. Trial of org 10172 in acute stroke treatment. Stroke. 1993;24:35-41.

22. Kong FYTW, Hao ZL, Liu M. Predictors of one-year disability and death in Chinese hospitalized women after ischemic stroke. Cerebrovasc Dis. 2010;29: 255-62.

23. Brott T, Adams HP, Olinger CP, Marler JR, Barsan WG, Biller J, Spilker J, Holleran R, Eberle R, Hertzberg V. Measurements of acute cerebral infarction: a clinical examination scale. Stroke. 1989;20:864-70.

24. Ott BR, Zamani A, Kleefield J, Funkenstein $\mathrm{HH}$. The clinical spectrum of hemorrhagic infarction. Stroke. 1986:17(4):630-7.

25. Kernan WN, Viscoli CM, Brass LM, Broderick JP, Brott T, Feldmann E, Morgenstern LB, Wilterdink JL, Horwitz RI. Phenylpropanolamine and the risk of hemorrhagic stroke. N Engl J Med. 2000;343:1826-32.

26. Liu S, Wang X, Lu Y, Li T, Gong Z, Sheng T, Hu B, Peng Z, Sun X. The effects of intraoperative cryoprecipitate transfusion on acute renal failure following orthotropic liver transplantation. Hepatol Int. 2013;7:901-9.

27. Sohal AS, Gangji AS, Crowther MA, Treleaven D. Uremic bleeding: pathophysiology and clinical risk factors. Thromb Res. 2006;118:417-22.

28. Molshatzki N, Orion D, Tsabari R, Schwammenthal Y, Merzeliak O, Toashi M, Tanne D. Chronic kidney disease in patients with acute intracerebral hemorrhage: association with large hematoma volume and poor outcome. Cerebrovasc Dis. 2011;31:271-7.

29. Berger PB, Best PJ, Topol EJ, White J, Di Battiste PM, Chan AW, Kristensen SD, Herrmann HC, Moliterno DJ. The relation of renal function to ischemic and bleeding outcomes with 2 different glycoprotein IIb/llla inhibitors: the do Tirofiban and ReoPro give similar efficacy outcome (TARGET) trial. Am Heart J. 2005;149:869-75.

30. Ikram MA, Vernooij MW, Hofman A, Niessen WJ, van der Lugt A, Breteler MM. Kidney function is related to cerebral small vessel disease. Stroke. 2008;39:55-61.

31. Cho AH, Lee SB, Han SJ, Shon YM, Yang DW, Kim BS. Impaired kidney function and cerebral microbleeds in patients with acute ischemic stroke. Neurology. 2009;73:1645-8.

32. Vandenbroucke JP, von Elm E, Altman DG, Gotzsche PC, Mulrow CD, Pocock SJ, Poole C, Schlesselman JJ, Egger M. Strengthening the reporting of observational studies in epidemiology (STROBE): explanation and elaboration. PLoS Med. 2007:4:e297.

33. Callahan A, Amarenco P, Goldstein LB, Sillesen $H$, Messig M, Samsa GP, Altafullah I, Ledbetter LY, MacLeod MJ, Scott R, Hennerici M, Zivin JA, Welch KM. Risk of stroke and cardiovascular events after ischemic stroke or transient ischemic attack in patients with type 2 diabetes or metabolic syndrome: secondary analysis of the stroke prevention by aggressive reduction in cholesterol levels (SPARCL) trial. Arch Neurol. 2011;68:1245-51.

34. Ergul A, Kelly-Cobbs A, Abdalla M, Fagan SC. Cerebrovascular complications of diabetes: focus on stroke. Endocr Metab Immune Disord Drug Targets. 2011;12(2):148-58

35. Acampa M, Camarri S, Lazzerini G, Tassi R, Valenti R, Cartocci A, Martini G. Increased arterial stiffness is an independent risk factor for hemorrhagic transformation in ischemic stroke undergoing thrombolysis. Int J Cardiol. 2017:243:466-70

36. Ong CT, Wong YS, Wu CS, Su YH. Atrial fibrillation is a predictor of inhospital mortality in ischemic stroke patients. Ther Clin Risk Manag. 2016;12: 1057-64.

37. Zhang PL, Wang YX, Chen Y, Zhang $\mathrm{CH}$, Li CH, Dong Z, Zhang SS, Tong YF, Li YQ, Tong XG, Wang JH. Analysis on the correlation factors for hemorrhagic transformation after intravenous thrombolytic therapy. Eur Rev Med Pharmacol Sci. 2015:19(6):1001-8.

38. Desilles JP, Syvannarath V, Ollivier V, Journe C, Delbosc S, Ducroux C, Boisseau W, Louedec L, Di Meglio L, Loyau S, Jandrot-Perrus M, Potier L, Michel JB, Mazighi M, Ho-Tin-Noé B. Exacerbation of thromboinflammation by hyperglycemia precipitates cerebral infarct growth and hemorrhagic transformation. Stroke. 2017;48:1932-40.

39. Mazya M, Egido JA, Ford GA, Lees KR, Mikulik R, Toni D, Wahlgren N, Ahmed N. Predicting the risk of symptomatic intracerebral hemorrhage in ischemic stroke treated with intravenous alteplase: safe implementation of treatments in stroke (SITS) symptomatic intracerebral hemorrhage risk score. Stroke. 2012;43:1524-1531.

40. Hafez S, Abdelsaid M, El-Shafey S, Johnson MH, Fagan SC, Ergul A. Matrix metalloprotease 3 exacerbates hemorrhagic transformation and worsens functional outcomes in hyperglycemic stroke. Stroke. 2016:47:843-51.

41. McBride DW, Legrand J, Krafft PR, Flores J, Klebe D, Tang J, Zhang JH. Acute hyperglycemia is associated with immediate brain swelling and hemorrhagic transformation after middle cerebral artery occlusion in rats. Acta Neurochir Suppl. 2016:121:237-41.

42. O'Rourke MF, ME S. Relationship between aortic stiffening and microvascular disease in brain and kidney: cause and logic of therapy. Hypertension. 2005;46:200-4

43. Alex M, Baron EK, Goldenberg S, Blumenthal HT. An autopsy study of cerebrovascular accident in diabetes mellitus. Circulation. 1962:25:663-73.

44. Stratton IM, Adler Al, Neil HA, Matthews DR, Manley SE, Cull CA, Hadden D, Turner RC, Holman RR. Association of glycaemia with macrovascular and microvascularcomplications of type 2 diabetes (UKPDS 35): prospective observational study. BMJ. 2000:321:405-12.

45. Danne T, Weber B, Dinesen B, Mortensen HB. Threshold of HbA1cfor the effect of hyperglycemia on the risk of diabetic microangiopathy. Diabetes Care. 1996;19:183.

\section{Ready to submit your research? Choose BMC and benefit from:}

- fast, convenient online submission

- thorough peer review by experienced researchers in your field

- rapid publication on acceptance

- support for research data, including large and complex data types

- gold Open Access which fosters wider collaboration and increased citations

- maximum visibility for your research: over $100 \mathrm{M}$ website views per year

At $\mathrm{BMC}$, research is always in progress.

Learn more biomedcentral.com/submissions 